\title{
Digital twins: artificial intelligence and the loT cyber-physical systems in Industry 4.0
}

\author{
Petar Radanliev ${ }^{1}$ (D) David De Roure ${ }^{1} \cdot$ Razvan Nicolescu $^{2} \cdot$ Michael Huth $^{3} \cdot$ Omar Santos $^{4}$
}

Received: 26 November 2020 / Accepted: 22 April 2021 / Published online: 24 May 2021

(c) The Author(s) 2021

\begin{abstract}
This paper presents a summary of mechanisms for the evolution of artificial intelligence in 'internet of things' networks. Firstly, the paper investigates how the use of new technologies in industrial systems improves organisational resilience supporting both a technical and human level. Secondly, the paper reports empirical results that correlate academic literature with Industry 4.0 interdependencies between edge components to both external and internal services and systems. The novelty of the paper is a new approach for creating a virtual representation operating as a real-time digital counterpart of a physical object or process (i.e., digital twin) outlined in a conceptual diagram. The methodology applied in this paper resembled a grounded theory analysis of complex interconnected and coupled systems. By connecting the human-computer interactions in different information knowledge management systems, this paper presents a summary of mechanisms for the evolution of artificial intelligence in internet of things networks.
\end{abstract}

Keywords Digital twin · Industrial internet of things · Cyber physical systems $\cdot$ Human and robot interactions $\cdot$ Industry $4.0 \cdot$ Bibliometric analysis

\section{Introduction}

The volume of data generated at the edge, creates diverse challenges for developing data strategies in a variety of areas (e.g., artificial intelligence, ethics, edge vs fog computing). Data strategies for complex coupled systems at the edge, demands data strategy optimisation for collecting of probabilistic data, when edge computing nodes are deployed. The personal perceptions of risk as a result of collecting probabilistic data at the edge interact with data regulations, standards and policies. The focus of the empirical research (in Sect. 3) of this study is the integration of these data

Petar Radanliev

petar.radanliev@eng.ox.ac.uk

1 Oxford E-Research Centre, Engineering Science Department, University of Oxford, 7 Keble Rd, Oxford OX1 3QG, England, UK

2 Department for Anthropology, UCL, London, England, UK

3 Department of Computing, Imperial College London, Huxley Building, 180 Queen's Gate, London SW7 2AZ, England, UK

4 Cisco Research Centre, Research Triangle Park, Durham-Raleigh, North Carolina, USA perceptions, regulations and policies for conceptualising the creation of 'digital twins'. Our research objective is to apply statistical methods on existing research records and to identify how artificial intelligence (AI), is evolving at the edge. With consideration of the above, our research focus was on AI integration in 'cyber-psychical systems' (CPS) that connect human-computer interactions. Our research emphasis was on conceptualisation of AI assimilation in 'digital twins' of CPS - that meets public acceptability, security standards, and legal scrutiny. This paper builds upon earlier literature on cyber risk in Industry 4.0 (I4.0) (Radanliev et al. 2020a, b, c, d), but with less focus on supply chains and much greater emphasis on statistical biometrical analysis of large number of data records and qualitative empirical analysis of the leading Industry 4.0 national frameworks.

To address these research objectives, the paper integrates the topics of artificial intelligence and cyber physical systems with areas including 'Industry 4.0' (I4.0)—which represent the digitalisation of industrial processes; 'internetof-things' (IoT) - which is defined as connected system (Fig. 1).

The paper builds upon established methodologies (1) literature review and bibliometric analysis to identify concepts from existing research. (2) empirical review of most 


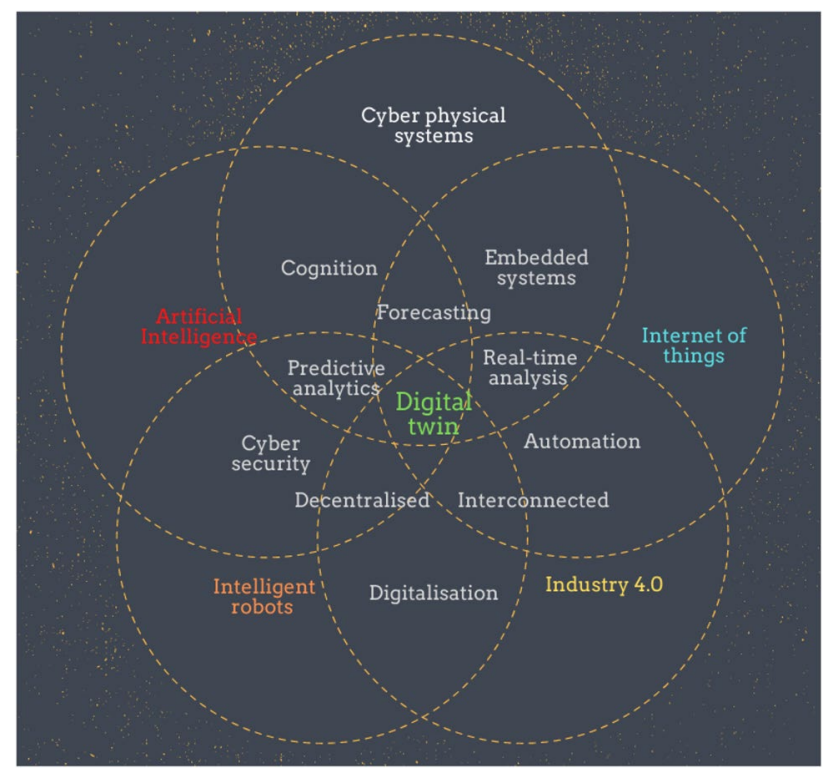

Fig. 1 Research (mind-map) plan

documented frameworks and initiatives on Industry 4.0; (3) grounded theory, to identify and group concepts from the literature review, bibliometric analysis, and the empirical analysis, followed by (4) conceptual diagram design to present the new process.

The reminder of the paper is structured as follow: In Sect. 2 we present a literature review on challenges for privacy, security and resilience of connected environments, and future challenges for AI systems embedded within IoT. We conclude Sect. 2 with a bibliometric analysis, using statistical software and $\mathrm{R}$ studio to present three-fields plot, collaboration network map, and conceptual research structure map with using factorial analysis. In Sect. 3 we present our empirical analysis, where the results of applying grounded theory, for conceptual groupings, are presented in summary tables and followed by conceptual diagram illustration. Followed by a discussion in Sect. 4, and conclusions in Sect. 5.

\section{Literature review}

The objective of the qualitative investigation is to review a selected article that are considered as leading academic research in this area. The objective of the quantitative analysis is to review all current and historical data records. In our literature review and bibliometric analysis, we followed recommendations on ensuring 'relevance' of the analysed literature (Lezzi et al. 2018), accuracy through 'text mining' (Rivas et al. 2018), with a focus on 'integration' of different technologies (Sittón-Candanedo 2020).

\subsection{Present challenges for privacy, security and resilience of connected environments}

Present challenges for artificial intelligence in industrial techniques are in the areas of: robustness, safety, and security (Hahn et al. 2013; Zhu et al. 2011); control and hybrid systems (Leitão et al. 2016; Shi et al. 2011); computational abstractions architectures (Madakam et al. 2015); realtime embedded systems abstractions (Marwedel and Engel 2016; Radanliev et al. 2020a); model-based development (Jensen et al. 2011) and education and training (Faller and Feldmüller 2015). However, as the artificial cognition in cyber-physical systems (CPS) is an evolutionary process (Wahlster et al. 2013), the challenges will be evolving with time (Radanliev et al. 2020a, b, c, d), which requires flexibility management of the complexities of the CPS. In addition to the evolving challenges, for creating a reliable, secure and economically sustainable power system, financial planning arrangements should be developed for CPS applications, e.g. Sentinel (Balaji et al. 2015)—can be used to exploit the information flow for energy savings.

\subsection{Future challenges for Al systems embedded within loT}

Building upon the present challenges, futuristic artificial cognition in CPS requires the deployment of self-sustaining networked sensors and actuators (Rajkumar et al. 2010) operating in symbiotic relations with the physical environment modelled through a user-centric Cloud (Gubbi et al. 2013). Environmental natural resources are crucial in sustaining economic development (Stock and Seliger 2016), and CPS in the future should be focused on creating eco-industrial by-product synergy (Pan et al. 2015).

Another challenge is the evolution into self-adapting cognitive decentralised CPS. This process would present a distributed (Wan et al. 2015) and integrated-decentralised CPS swarm intelligence, based on cooperation of large population of simple agents (Stojmenovic 2014). The decentralisation of the control function to a swarmwhich implies lack of central control dictating individual behaviour and interactions among swarm agents-stimulates the emergence of intelligent global behaviour. Individual agents exploit cloud services to analyse, predict, optimise and mine scalable capabilities of historical data and enable applications to self-adjust their behaviour to self-optimise their own performance (Brettel et al. 2016; Shafiq et al. 2015). In such decentralised systems, individual agents' 'contract-based design' is applied before 'platform-based design' (Sangiovanni-Vincentelli et al. 2012). 
Contract-based design enables actor-oriented design of multiple models of computation to be integrated in a single hierarchical system (Bhave et al. 2011), like loosely timetriggered CPS architectures (Benveniste 2010).

\section{Methodology for the bibliometric analysis of existing literature with computable statistical methods}

In this section, we analyse existing literature records with computable statistical methods. While the literature review was focused on qualitative review of selected articles, this chapter analyses data records with statistical categorisations that eliminate bias of qualitative interpretations, and data records selection. To analyse the present and future challenges identified in the literature review, we conducted a bibliometric search for data records. We searched the Web of Science Core Collection for records on the TOPIC: (cyber physical systems) AND TOPIC: (internet of things) AND TOPIC: (industry 4.0). This search resulted with 436 in a timespan from 1900 to 2020 . We obtained the data from the Web of Science with a Boolean search that include only 'AND'. In the spirit of reproducible research, we note that if similar search is conducted, but instead of AND, we use OR, then the results would be 60,148 . These records would however not be related to a research related to all the topics of IoT, CPS and I4.0, but instead, the data records would be relevant to individual topics. Since in this study, we wanted to investigate the relationship between these systems, we used the smaller sample of 436 data record. This was based on our rationale to investigate the relationship between these topics, and not the research on these topics in isolation. Since we wanted to investigate the tacit evolution of AI in these connected systems, we did not include $\mathrm{AI}$ in the data records search, instead, our investigation was on identifying if concepts related to $\mathrm{AI}$ are present in the data records. We wanted to investigate if $\mathrm{AI}$ is evolving naturally as a result of the relationships between these connected systems. To analyse the data records, we used statistical methods with $\mathrm{R}$ studio and the 'bibliometrix' package (Aria and Cuccurullo 2017), see Fig. 2.

In Fig. 2, we designed a three-fields plot of the 436 data records, and we can see the connections between different research topics by keywords, by fields, and by countries. In the spirit of reproducible research and eliminating bias in research, we include one figure analysis where the data search and analysis is conducted with the Web of Science research analysis tool, but instead of AND, we use OR, and we analyse the results of 60,148 records on these subjects, but with individual topic investigated, which can be replicated by searching for the TOPIC: (cyber physical systems) OR TOPIC: (internet of things) OT TOPIC: (industry 4.0), in Fig. 3.

In Fig. 3, we can see that China has produced the most scientific research on the individual topics in isolation.

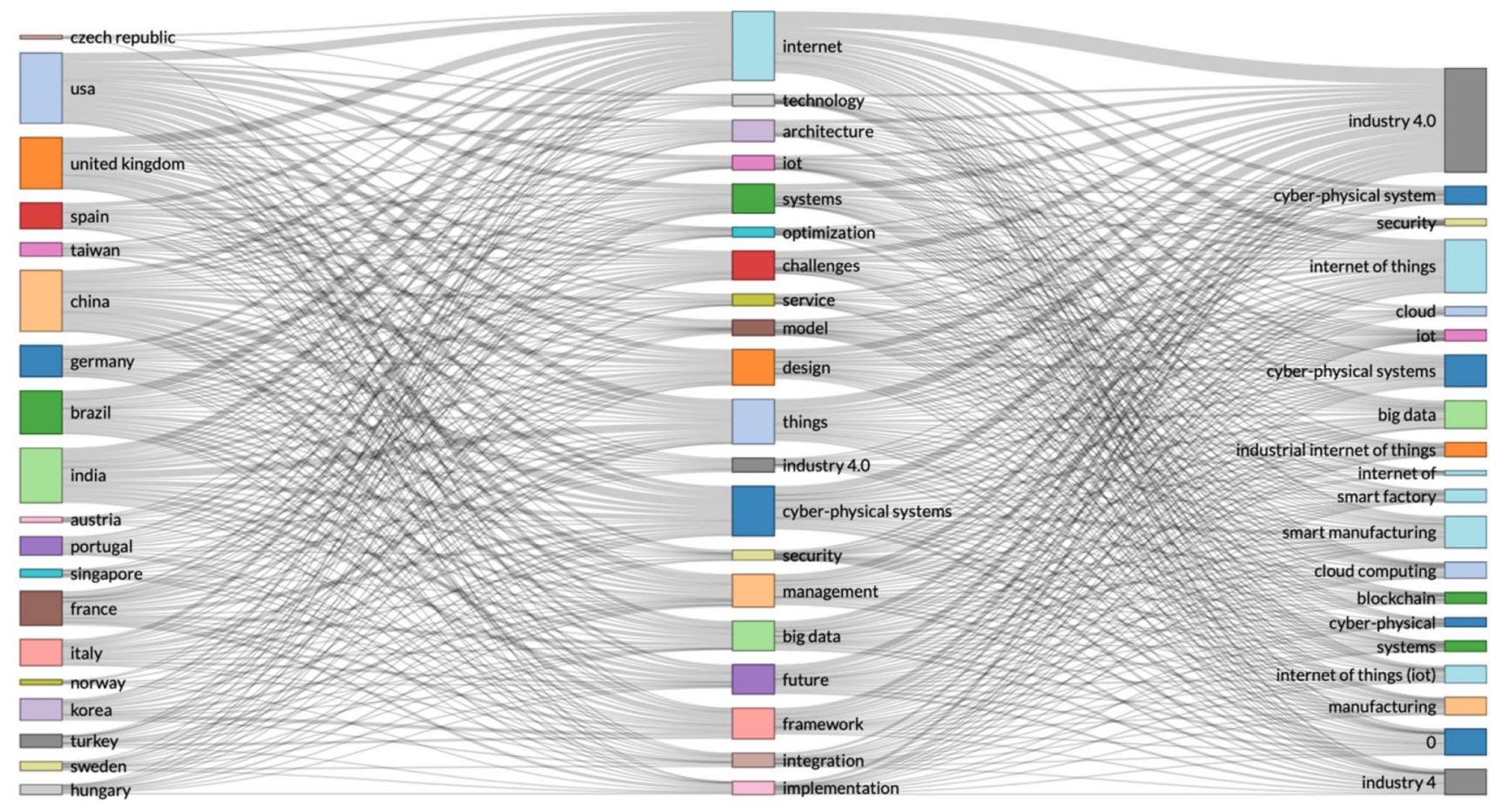

Fig. 2 Bibliometric analysis of 436 data records - three-fields plot 


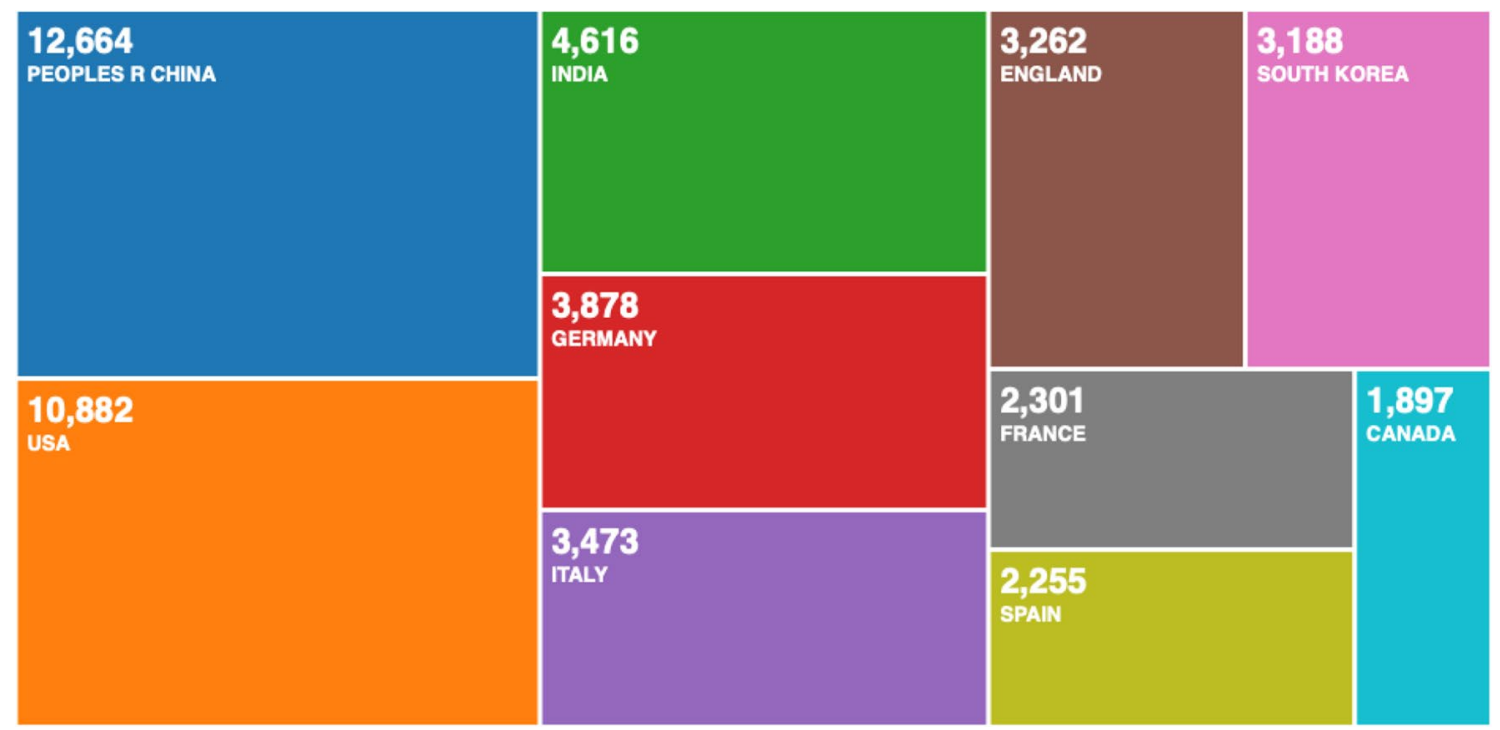

Fig. 3 Bibliometric analysis with the Web of Science research analysis tool on the TOPIC: (cyber physical systems) OR TOPIC: (internet of things) OT TOPIC: (industry 4.0)

While on the three-field plot (Fig. 2) we can see that US and China have produced a comparative number of records on these topics in combination, what is puzzling is that in Fig. 2, the UK and Brazil are also strongly represented. While in Fig. 3, Germany and Italy score higher than the $\mathrm{UK}$, and Brazil is not even in the top countries selected by the We of Science research analysis of the 60,148 records. Therefore, we continued the statistical analysis of the bibliometric records. Although the three-fields plot in Fig. 2 is very detailed in visualising the connections between research keywords, fields, and relating them by countries, we could not identify the collaborations between countries. To analyse which counties collaborate in the fields of IoT, CPS, and I4.0, we created a collaboration network map Fig. 4.

From the collaboration network map, we can see the historical and present collaboration relationships on the topics of IoT, CPS and I4.0. For example, China is working closely with Singapore, a cluster is visible between Brazil, Portugal, Spain, France and Romania, and a second cluster between Germany, Turkey, Sweden and Austria. These clusters are expected, because they also represent know clusters based on culture, economy, tourism, etc. However, the most unexpected cluster is visible in the red colour, strongly representing the UK, USA and China. Since the UK has been in the EU until 2019, one would have expected a stronger cluster between the UK and other EU countries, like Germany. Perhaps this can be explained by language and cultural similarities between the UK and USA. The relationship between the US and China, could possibly be explained by economic factors. To analyse further this data records, we developed a conceptual structure map in Fig. 5.

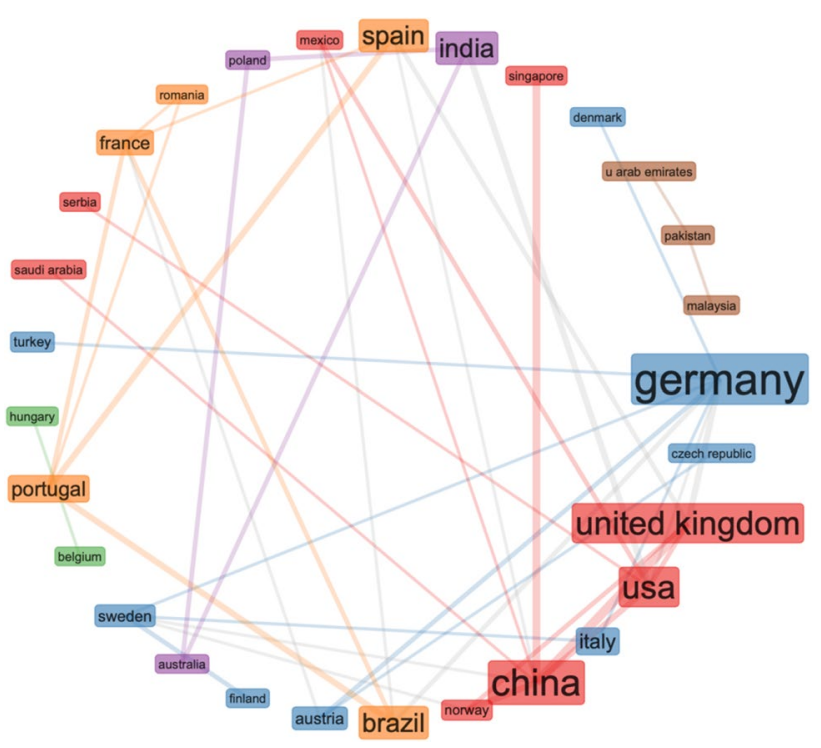

Fig. 4 Bibliometric analysis of 436 data records-collaboration network

The conceptual structure map in Fig. 5 is designed with applying factorial analysis. We wanted to see how closely are related the keywords and research fields from the three-fields plot in Fig. 2. In the three-fields plot, we could only see the connections, but we could not see how closely if these areas are related. In the Fig. 5, conceptual structure map, we can see how close or distant are specific research areas. We complimented the statistical analysis with literature review analysis to categorise emerging themes for embedding AI systems within IoT systems. 


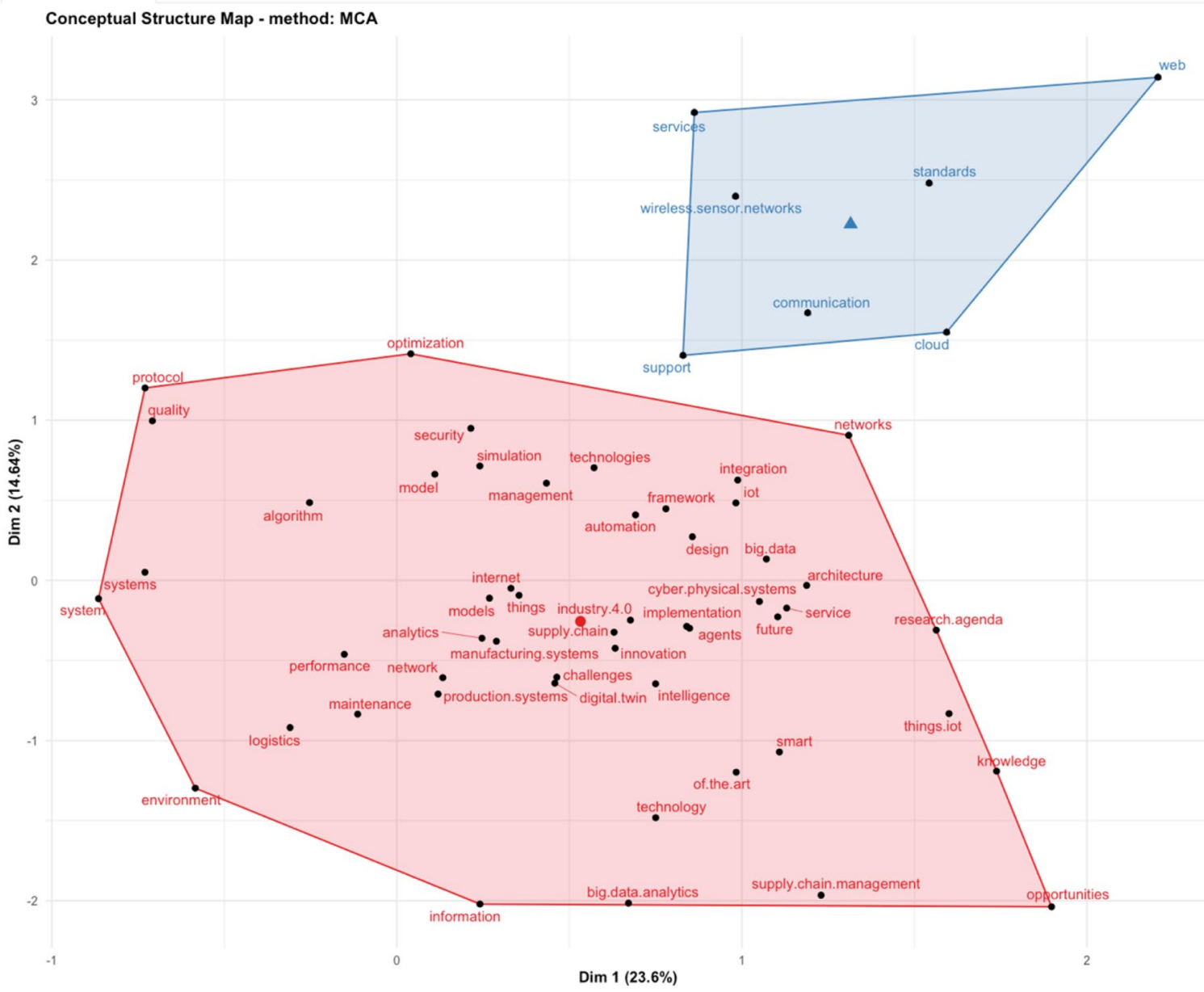

Fig. 5 Bibliometric analysis of 436 data records-factorial analysis

\section{Categorisation of future and present techniques: found in the qualitative literature review and the quantitative bibliometric analysis}

This review presents different groups of future challenges and techniques for embedding AI systems within IoT systems, and a form of dependency or a causal edge relation between them. Table 1 shows the edges between different nodes representing groups of the influence of future and present challenges and techniques on artificial cognition in CPS.

The techniques identified (in Table 1) represent a form of conceptual grouping for building upon the CPS architecture (Lee et al. 2015), but separates the future from the present techniques and challenges. This separation constitutes the grounding for the empirical review of AI systems within IoT systems summarised in Tables 2, 3 and 4, presenting an overview of I4.0 strategies in tabular form. Table 1 is also important for the understanding of the conceptual diagram, in Fig. 6, because all abbreviations are explained in Table 1.

\section{Empirical review: embedding loT systems in 14.0 frameworks}

The aim of this section is to relate the academic literature and industry reports, with what is happening in practice. The first objective of the empirical review is to determine whether the practical frameworks and initiative globally are implementing the recommendations from the leading research in this area, as identified in the literature reviewSect. 2. The second objective is to relate the findings from the bibliometric analysis, with the leading frameworks and initiatives, and to build summary tables of the emerging categories. The summary tables are used for the conceptual diagram design, illustrating the evolution of Industry 4.0 and IoT enhanced cyber-physical systems. Finally, by empirically comparing academic literature with national frameworks, we propose a practical approach, which is considered crucial in current literature (Radanliev, De Roure, Nurse, et al., 2020), and also discussed in earlier supply chain literature (Radanliev 2016). 
Table 1 Future and present techniques for embedding AI systems within IoT systems

\begin{tabular}{ll}
\hline Present techniques and challenges & \\
Education and training & EaT \\
Financial planning & FP \\
Information flow for energy savings & IFfES \\
Robustness, safety, and security & RSS \\
Control and hybrid systems & CHS \\
Computational abstractions architecture & CAA \\
Real-time embedded systems abstractions & RTESA \\
Model-based development & MBD \\
Future techniques and challenges & \\
Eco-industrial by-product synergy & EIS \\
Distributed integrated-decentralised & DID \\
Multi-agent swarm intelligence & SI \\
Contract-based design & CBD \\
Self-sustaining networked sensors & SSS \\
Symbiotic relations with the physical environment & SRPE \\
User-centric Cloud based vision & CCV \\
Future vision for artificial cognition in CPS & \\
Energy-aware buildings and cities & EABaC \\
Critical infrastructure with preventive maintenance & CIPM \\
Self-correcting of cyber-physical systems & SCCPS \\
Flexible AC transmission systems & FACTS \\
Distributed energy resource technologies & DER \\
\hline
\end{tabular}

The empirical review starts with the German I4.0 (Industrie 4.0) (Germany Trade Invest 2014; Industrie 4.0, 2017) and follows with an empirical review of (additional 13) I4.0 initiatives. The main elements of each initiative in Table 3 are separated in: areas of focus, decision and action. The empirical review identifies several shortcomings in individual initiatives, which are complimented by other initiatives. This required building a model that integrates the strengths and reduces the weaknesses of all initiatives. There are problems, when, for example, some of the areas of focus, decision and action (Tables 2, 3,4) differ in terms of strategy and propose very different approaches. To resolve this issue, we use two strategies. Firstly, the individual areas as categorised in the empirical summary tables that are used as reference categories. Secondly, the summary tables are used for embedding AI systems within IoT systems in I4.0 mechanism that relates various areas to each other and eliminates conflicts in different and sometimes contrasting approaches.

The summary table analysis of the initiatives presents some of the complexities in developing a unifying architecture, with a step-by-step method for integration of CPS cognitive capabilities. The diversity of the approaches in world initiatives grows in magnitude as the empirical analysis advances to the summary tables of the less evolved (Table 3 ) and the elusive initiatives (Table 4). This diversity is categorised with the grounded theory, into areas of 'focus', 'decision', and 'action'. Some initiatives contain concepts that are based on prioritising, and we created a category called 'priority' for such concepts. Or prioritised 'relationships', so we created a separate group for such concepts. In the summer tables, we present a multiverse of such categories that emerge from applying the grounded theory in the empirical analysis. Some of these areas appear unrelated, and yet, they are present. Therefore, the relationship is not clearly presented in the national initiative, but it becomes clearer in the summary table, when placed in a category against other similar concepts.

The differences in the categorised approaches in the three summary tables correspond to the different national and international strengths and aspirations of the promoters of these strategies. The three summary tables (Tables 2, 3, 4) emerging from the empirical review, capture different and often conflicting approaches that harden adoption of coherent standards for artificial cognition in CPS.

The conceptual diagram in Fig. 6 separates the future challenges from the present challenges in the three summary tables (Tables 2, 3, 4). The categorisations in the summary tables (Tables 2, 3, 4), detail our grounded theory process, where emerging concepts are extracted from the large number of digitalisation initiatives from around the globe. The emerging concepts are structured in a conceptual diagram, using categorical coding in Fig. 6. To understand better the conceptual diagram, in Fig. 6, we refer to the abbreviations in Table 1.

In Fig. 6 to simplify the differences between areas of: 'focus', 'decision' and 'action', we used the world leading initiatives, and grouped concepts based on similarities, e.g. in the key technologies: NIF lists 47 key technologies, Made in China 2025 prioritises 10 tech sectors and NTI includes 13 key tech examples. However, some initiatives focus on areas of decision and action that differ greatly from the main objectives of other initiatives. For example, the focus on market networks and market creation of the National Technology Initiative (ASI 2016) is opposed to the mainstream technology development in NIF that includes policies for subsidies and repayable advances, tax incentives and loans. These differences emphasised the need to develop the summary tables that serve as a mechanism for inter-relating the three areas of focus, decision and action in a meaningful method. The analysis outlined in Tables 2, 3 and 4 provides detailed explanation of these areas.

\section{Discussion}

Through empirical and statistical analysis, we presented a new understanding on how artificial intelligence technologies are migrated to the periphery of the internet and into local internet of things networks. With qualitative 


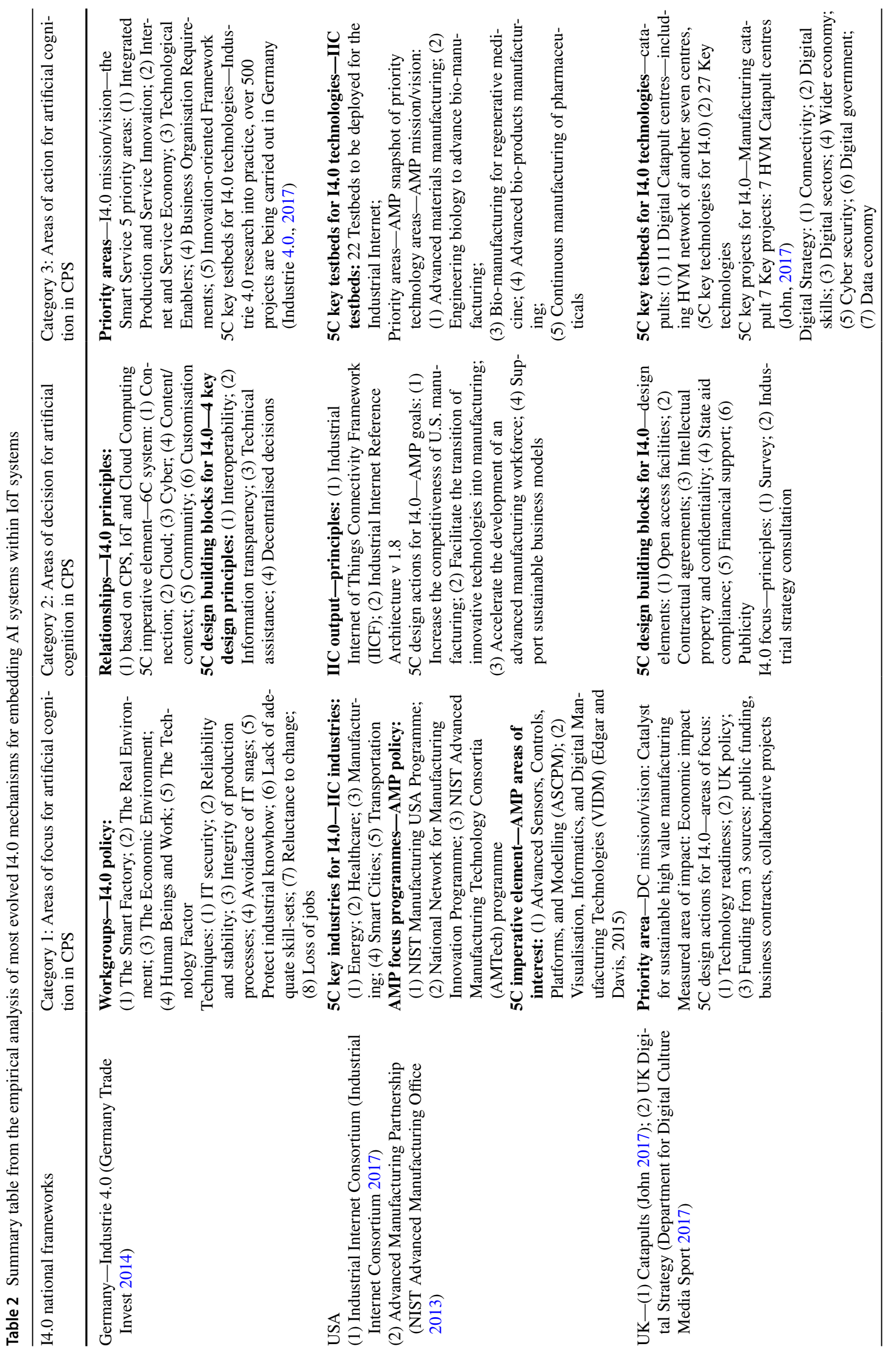




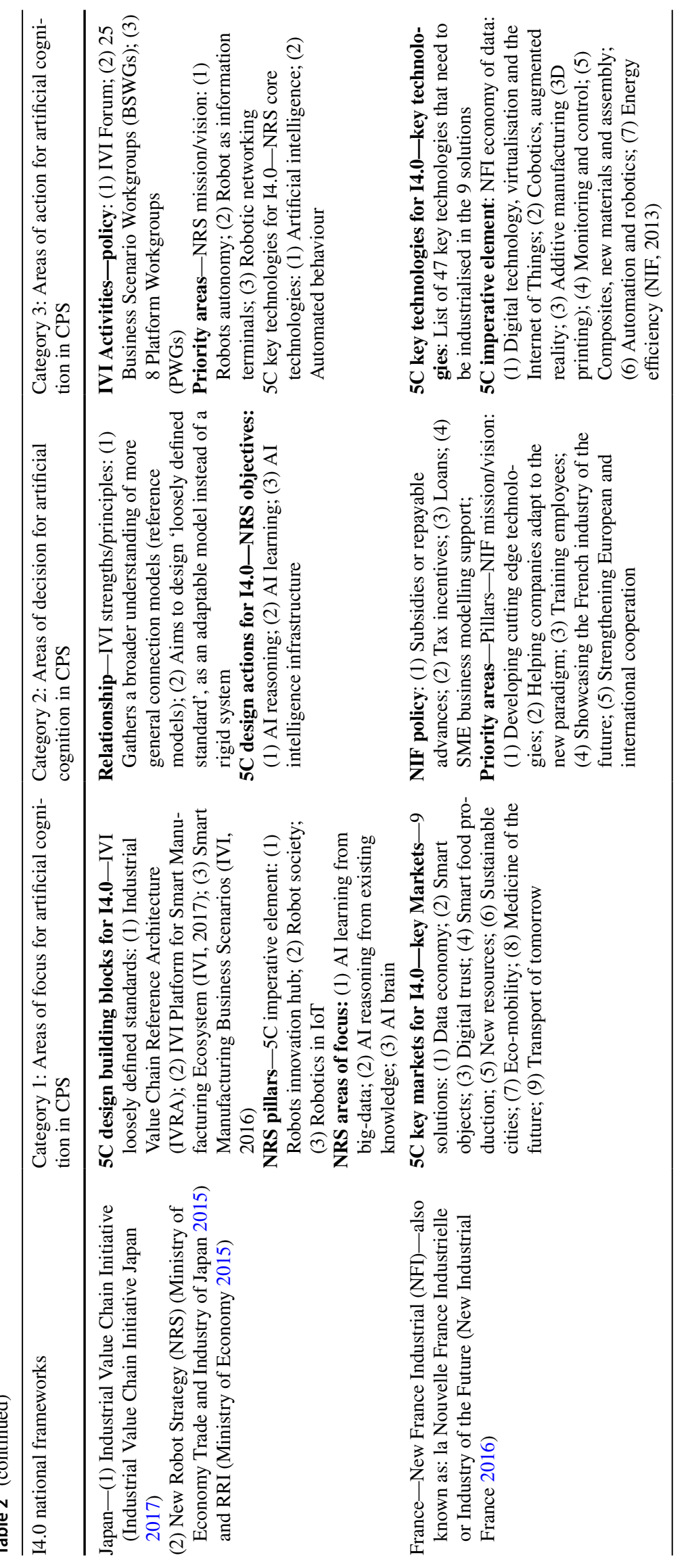




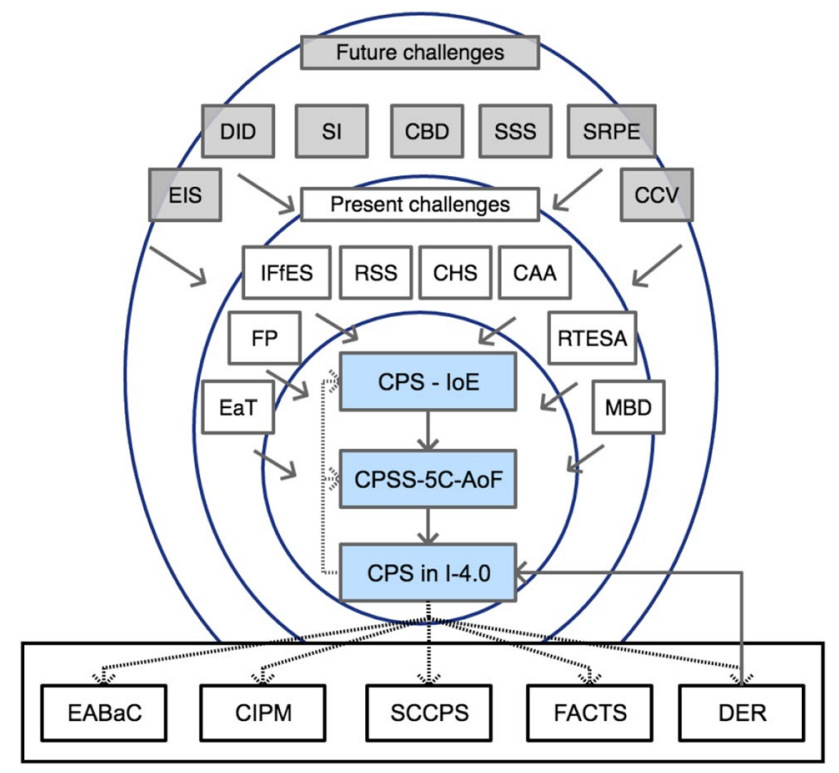

Fig. 6 Future and present challenges separated in a conceptual diagram-explaining the mechanism that enables understanding of how AI evolves within the IoT

investigation, we identified that artificial intelligence improves organisational resilience in industrial systems, supporting both a technical and human level. With empirical analysis, we correlated the world leading Industry 4.0 frameworks, and modelled the interdependencies between edge components to both external and internal services and systems in summary tables. The methodology we applied resembled a grounded theory analysis of complex interconnected and coupled systems. This enables us to connect the human-computer interactions in different information knowledge management systems with artificial intelligence, and to design a mechanism for future evolution of artificial intelligence in internet of things networks. We argue that such evolution is inevitable, and already happening in Industry 4.0 automations.

In this review study, we combined qualitative review of recent and relevant literature from Google Scholar, with quantitative computable statistical analysis of bibliometric data records from the Web of Science, and empirical review of government frameworks. The findings from this review study is an outline of present and future research challenges in Sects. 2.1 and 2.2, analysed with the bibliomic analysis in Sect. 3 and summarised in Table 1. In Table 1, we can see the present and future research challenges categorised and abbreviated as terminology for building the conceptual diagram in Fig. 6, presenting the state-of-the-art in our understanding on how AI evolves within the IoT.

The implications for research are a conceptual approach that enables us to connect the human-computer, with the evolution of artificial intelligence in connected networks. We argue that such evolution is inevitable, and already happening in Industry 4.0 automations.

The future research dimensions emerging from this study are related to enhancing our capacity for understanding of the opportunities when AI technologies are integrated in smart connected networks. To assist in these future dimensions, the summary tables developed throughout the paper, can serve as a best practice and inform initial steps taken for design and prototype of AI-enabled IoT. AI-enabled IoT would enable a comprehensive and systematic understanding of the opportunities and threats that arise when AI technologies are migrated to the periphery of the internet and into local IoT networks. The summary tables detail a new CPS process, that enables practitioners to understand and design deep learning solutions for embedding AI systems. Recent research has discussed the integration and the cyber risks from Fog computing (FC) and Internet of Everything (IoE) (Radanliev et al. 2020a). This research was focused on CPS process in Edge computing and Internet of Things. The new CPS process can be applied in real systems like smart cites and 5G technology, with the integration of IoT connected systems. These systems (IoT and CPS) are interconnected and the results in Fig. 1 present hierarchical categories integrating the two systems.

The main implications for practitioners from this study, is the new CPS process. When enhanced with recent deep learning solutions, the new CPS process can be applied in real systems like smart cites and 5G technology. The new CPS process can also help governments trying to improve and/or build their national strategies. The value from the developed mechanisms for national governments of the developed nations, is that they can check and compare the existing digital strategies with the national digital strategies applied across the globe.

The findings from this study benefit digital industries in developed and developing nations, with a design process describing how to use the new CPS process in industrial applications. The benefits for digital industries in developing countries that have no digital strategies (e.g., most African, Latin American, Eastern European nations), is that they can review the current developments from around the world, and follow the step by step process to embed AI systems within IoT systems of their I4.0 frameworks. The benefits for digital industries in developed countries is included in the summary tables, which are presented in this paper and are designed to support the building of future artificial cognition in CPS and the improving and reformulating of existing I4.0 frameworks and practical initiatives. The summary table mechanism emerging from the empirical review is based on grouping of future and present techniques and presenting the design process for embedding AI systems within IoT systems. These are established models for decomposing and 


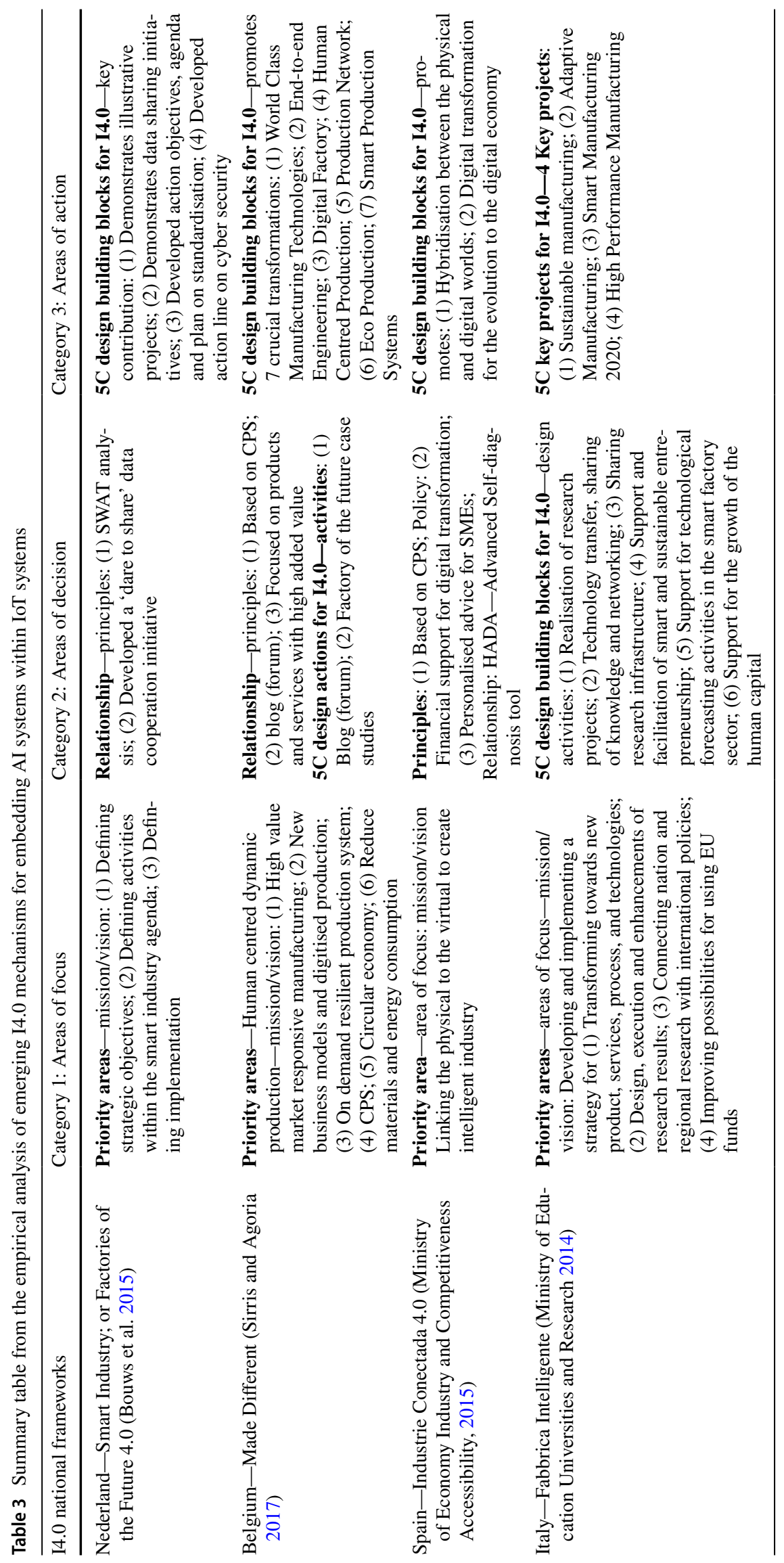




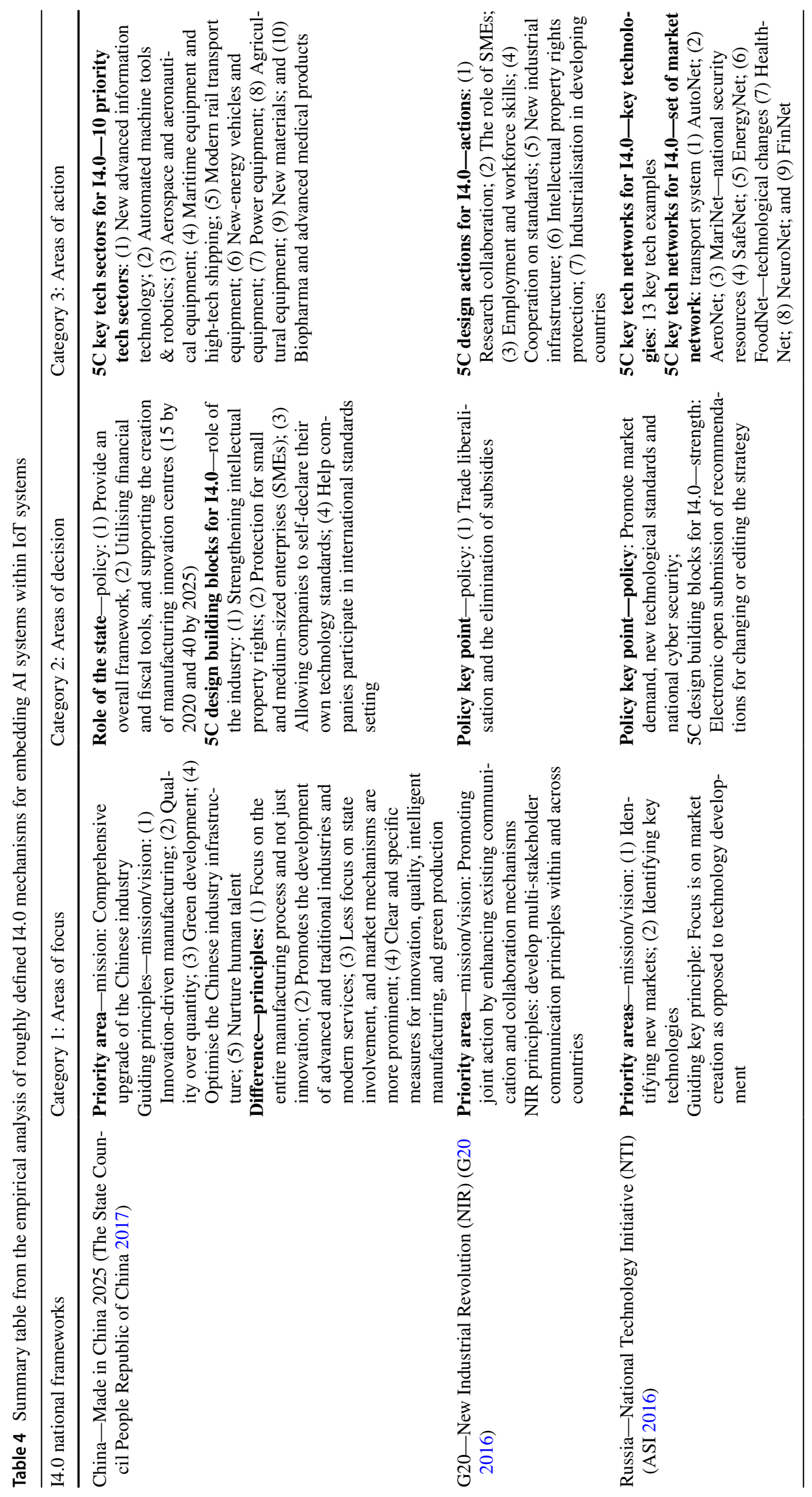


reverse engineering design processes that are present in this paper.

Validity of the research findings was pursued through applying the grounded theory approach (Goulding 2002), to create the categorisations in the summary tables, which is a time tested method for building theory from existing knowledge. For ensuring validity of the findings, we also applied qualitative research techniques, including open and categorical coding (Easterby-Smith et al. 2002; Eriksson and Kovalainen 2008; Gummesson 2000), in the summary tables. Open coding to validate a reliable representation of the data records, categorical coding to recognise the concepts in the data (Goulding 2002). Discourse analysis is applied to evaluate and interpret the connotation behind the explicitly stated approaches (Eriksson and Kovalainen 2008), along with tables of evidence (Eisenhardt 1989) as seen in the summary tables, and conceptual diagram (Miles et al. 1983) for graphical analysis.

\section{Conclusion}

The research integrates concepts related to digital automation (e.g., digital twins), that have not been previously integrated in a research. Through statistical analysis of bibliometric data records from 1900 to 2020, this study identified how artificial intelligence, is evolving in internet of things systems. With factorial analysis, we identified the main national clusters of research, on how artificial intelligence, is evolving in internet of things systems and cyberphysical systems. From our analysis, it becomes clear that despite political turbulences, the US is closely coupled in the research collaboration network with China. Furthermore, despite political and economic collaborations, that even include a joint research budget (Horizon 2020), the two leading European nations in terms of this research, the UK and Germany are not closely engaged in research collaborations on the topics of internet of things, cyber-physical systems and Industry 4.0. Other findings from this study include an up-to-date overview of existing and emerging advancements in the field of I4.0, from academic literature and governmental initiatives. This combines existing literature to derive common basic terminology and approaches and to incorporate existing standards into a new conceptual mechanism for embedding AI within IoT of I4.0. In this study, cyber-psychical systems are defined as connecting systems for human-computer interactions, and our research focus was on artificial intelligence that meets public acceptability, security standards, and legal scrutiny. Therefore, instead of simply presenting concepts, we presented summary tables with clear narratives showing the national frameworks that are compliant and meet public acceptability, security standards, and legal scrutiny. The summary tables categorise concepts from established frameworks, while the literature review and the bibliometric analysis categorise established scientific research data records.

The summary tables developed throughout the paper, can serve as a best practice and inform initial steps taken for design and prototype of digital twins CPSs in Industry 4.0. Such prototype would improve our capacity for a comprehensive and systematic understanding of the opportunities and threats that arise when CPS are migrated to the periphery of the internet and into local IoT networks.

Acknowledgements Eternal gratitude to the Fulbright Visiting Scholar Project.

Authors contributions Dr Petar Radanliev: main author; Prof. Dave De Roure: supervision; Omar Santos, Prof. Michael Huth: supervision, review and corrections, Razvan Nicolescu: review and corrections.

Funding This work was funded by the UK EPSRC [Grant number: EP/S035362/1] and by the Cisco Research Centre [Grant number CG1525381]

Availability of data and materials All data and materials included in the article.

Code availability N/A - no code was developed; code was however used for running the R Studio analysis.

\section{Declarations}

Conflict of interest On behalf of all authors, the corresponding author states that there is no conflict nor competing interest.

Open Access This article is licensed under a Creative Commons Attribution 4.0 International License, which permits use, sharing, adaptation, distribution and reproduction in any medium or format, as long as you give appropriate credit to the original author(s) and the source, provide a link to the Creative Commons licence, and indicate if changes were made. The images or other third party material in this article are included in the article's Creative Commons licence, unless indicated otherwise in a credit line to the material. If material is not included in the article's Creative Commons licence and your intended use is not permitted by statutory regulation or exceeds the permitted use, you will need to obtain permission directly from the copyright holder. To view a copy of this licence, visit http://creativecommons.org/licenses/by/4.0/.

\section{References}

Aria, M., Cuccurullo, C.: bibliometrix: an R-tool for comprehensive science mapping analysis. J. Informet. 11(4), 959-975 (2017). https://doi.org/10.1016/j.joi.2017.08.007

ASI, A. for strategic initiatives: National Technology initiative, Agency for Strategic Initiatives. Government of Russia (2016). https:// asi.ru/eng/nti/

Balaji, B., Al Faruque, M. A., Dutt, N., Gupta, R., \& Agarwal, Y.: Models, abstractions, and architectures. In: Proceedings of the 52nd Annual Design Automation Conference on-DAC '15, 1-6. https://doi.org/10.1145/2744769.2747936 (2015) 
Benveniste, A.: Loosely Time-Triggered Architectures for CyberPhysical Systems. 2010 Design, Automation \& Test in Europe Conference \& Exhibition, Dresden, 3-8 (2010). https://doi.org/ 10.1109/DATE.2010.5457246

Bhave, A., Krogh, B. H., Garlan, D., \& Schmerl, B.: View consistency in architectures for cyber-physical systems. In: 2011 IEEE/ACM Second International Conference on Cyber-Physical Systems, 151-160 (2011). https://doi.org/10.1109/ICCPS.2011.17

Bouws, T., Kramer, F., Heemskerk, P., Van Os, M., Van Der Horst, T., Helmer, S., Huveneers, S., Butter, M., Van Der Zee, F., Van Oort, S., Ypma, J., Mulder, G., Kotterink, B., De Heide, M.: Smart Industry: Dutch Industry Fit for the Future. (2015). https://doi. org $/ 527727$

Brettel, M., Fischer, F.G., Bendig, D., Weber, A.R., Wolff, B.: Enablers for Self-optimizing Production Systems in the Context of Industrie 4.0. Procedia CIRP 41, 93-98 (2016). https://doi.org/10.1016/j. procir.2015.12.065

Department for Digital Culture Media Sport: UK Digital Strategy 2017-GOV.UK; Department for Culture, Media and Sport (2017). https://www.gov.uk/government/publications/uk-digitalstrategy/uk-digital-strategy

Easterby-Smith, M., Thorpe, R., Lowe, A.: Management Research: An Introduction. SAGE, Thousand Oaks (2002)

Eisenhardt, K.M.: Building theories from case study research. Acad. Manag. Rev. 14(4), 532 (1989). https://doi.org/10.2307/258557

Eriksson, P., Kovalainen, A.: Qualitative Methods in Business Research. SAGE, Thousand Oaks (2008)

Faller, C., Feldmüller, D.: Industry 4.0 learning factory for regional SMEs. Procedia CIRP 32, 88-91 (2015). https://doi.org/10. 1016/j.procir.2015.02.117

G20: G20 New Industrial Revolution Action Plan. (2016). http:// g20chn.org/English/Documents/Current/201609/P020160908 738867573193.pdf

Germany Trade Invest. Industrie 4.0 Smart Manufacturing for the Future. (2014). https://www.gtai.de/GTAI/Content/EN/Inves t/_SharedDocs/Downloads/GTAI/Brochures/Industries/indus trie4.0-smart-manufacturing-for-the-future-en.pdf

Goulding, C.: Grounded Theory: A Practical Guide for Management, Business and Market Researchers. SAGE, Thousand Oaks (2002)

Gubbi, J., Buyya, R., Marusic, S., Palaniswami, M.: Internet of Things (IoT): a vision, architectural elements, and future directions. Futur. Gener. Comput. Syst. 29(7), 1645-1660 (2013). https://doi.org/ 10.1016/j.future.2013.01.010

Gummesson, E.: Qualitative Methods in Management Research. Sage, Thousand Oaks (2000)

Hahn, A., Ashok, A., Sridhar, S., Govindarasu, M.: Cyber-physical security testbeds: architecture, application, and evaluation for smart grid. IEEE Trans. Smart Grid 4(2), 847-855 (2013). https:// doi.org/10.1109/TSG.2012.2226919

Industrial Internet Consortium: The Industrial Internet of Things Volume G5: Connectivity Framework; Industrial Internet Consortium. (2017). http://www.iiconsortium.org/pdf/IIC_PUB_G5_ V1.0_PB_20170228.pdf

Industrie 4.0.: Plattform Industrie 4.0-Testbeds. (2017). http://www. plattform-i40.de/I40/Navigation/EN/InPractice/Testbeds/testbeds. html

Industrial Value Chain Initiative Japan: Industrial Value Chain Reference Architecture; Industrial Value Chain Initiative. (2017). https://iv-i.org/en/docs/Industrial_Value_Chain_Reference_Archi tecture_170424.pdf

Jensen, J. C., Chang, D. H., Lee, E. A.: A model-based design methodology for cyber-physical systems. In: 2011 7th International Wireless Communications and Mobile Computing Conference, pp. 1666-1671 (2011). https://doi.org/10.1109/IWCMC.2011. 5982785
John, P.: High Value Manufacturing Catapult. (2017). https://ec. europa.eu/growth/tools-databases/regional-innovation-monitor/ sites/default/files/report/HighValueManufacturingCatapult_1.pdf

Lee, J., Bagheri, B., Kao, H.-A.: A cyber-physical systems architecture for industry 4.0-based manufacturing systems. Manuf. Lett. 3, 18-23 (2015). https://doi.org/10.1016/j.mfglet.2014.12.001

Leitão, P., Colombo, A.W., Karnouskos, S.: Industrial automation based on cyber-physical systems technologies: prototype implementations and challenges. Comput. Ind. 81, 11-25 (2016). https://doi.org/10.1016/j.compind.2015.08.004

Lezzi, M., Lazoi, M., Corallo, A.: Cybersecurity for Industry 4.0 in the current literature: a reference framework. In: Computers in Industry, vol. 103, pp. 97-110. Elsevier, Amsterdam (2018). https://doi. org/10.1016/j.compind.2018.09.004

Madakam, S., Ramaswamy, R., Tripathi, S.: Internet of things (IoT): a literature review. J. Comput. Commun. 3(3), 164-173 (2015). https://doi.org/10.4236/jcc.2015.35021

Marwedel, P., Engel, M.: Cyber-Physical Systems: Opportunities, Challenges and (Some) Solutions, pp. 1-30. Springer International Publishing, New York (2016). https://doi.org/10.1007/ 978-3-319-26869-9_1

Miles, M.B., Huberman, A.M., Saldaña, J.: Qualitative Data Analysis: A Methods Sourcebook. SAGE, Thousand Oak (1983)

Ministry of Economy Industry and Competitiveness Accessibility: Industria Conectada 4.0: La transformación digital de la industria española Dossier de prensa; Ministry of Economy Industry and Competitiveness Accessibility. (2015). http://www.lamoncloa. gob.es/serviciosdeprensa/notasprensa/Documents/081015Doss ierprensaIndustria4.0.pdf

Ministry of Economy Trade and Industry of Japan: NRS, New Robot Strategy-Vision Strategy and Action Plan; Ministry of Economy Trade and Industry of Japan. (2015). http://www.meti.go.jp/engli sh/press/2015/pdf/0123_01b.pdf

Ministry of Economy, T. and I. of J.: RRI, Robot Revolution Initiative-Summary of Japan's Robot Strategy -It's vision, strategy and action plan; Ministry of Economy, Trade and Industry of Japan. (2015). http://www.meti.go.jp/english/press/2015/pdf/ 0123_01c.pdf

Ministry of Education Universities and Research: Italian Technology Cluster: Intelligent Factories; Ministry of Education Universities and Research. Cluster Tecnologico Nazionale Fabbrica Intelligente I Imprese, Università, Organismi Di Ricerca, Associazioni e Enti Territoriali: Insieme per La Crescita Del Manifatturiero. (2014). http://www.fabbricaintelligente.it/en/

New Industrial France: New Industrial France: Building France's industrial future-updated text from the 2013 version. (2016). https://www.economie.gouv.fr/files/files/PDF/web-dp-indus-ang. pdf

NIST Advanced Manufacturing Office: Advanced Manufacturing Partnership. (2013). https://www.nist.gov/amo/programs

Pan, M., Sikorski, J., Kastner, C.A., Akroyd, J., Mosbach, S., Lau, R., Kraft, M.: Applying Industry 4.0 to the Jurong Island Ecoindustrial Park. Energy Procedia 75, 1536-1541 (2015). https:// doi.org/10.1016/j.egypro.2015.07.313

Radanliev, P.: Supply Chain systems architecture and engineering design: green-field supply chain integration. Int. J. Operat. Supply Chain Manag. (2016). https://doi.org/10.20944/preprints2 01904.0122.v1

Radanliev, P., De Roure, D., Nurse, J.R.C., Mantilla Montalvo, R., Cannady, S., Santos, O., Maddox, L., Burnap, P., Maple, C.: Future developments in standardisation of cyber risk in the Internet of Things (IoT). SN Appl. Sci. 2(2), 1-16 (2020a). https://doi.org/ 10.1007/s42452-019-1931-0

Radanliev, P., De Roure, D., Van Kleek, M., Santos, O., Ani, U.: Artificial intelligence in cyber physical systems. AI \& Soc. 1, 1-14 (2020b). https://doi.org/10.1007/s00146-020-01049-0 
Radanliev, P., De Roure, D., Walton, R., Van Kleek, M., Montalvo, R.M.R.M., Maddox, L.L.T., Santos, O., Burnap, P., Anthi, E.: Artificial intelligence and machine learning in dynamic cyber risk analytics at the edge. SN Appl. Sci. 2(11), 1-8 (2020c). https:// doi.org/10.1007/s42452-020-03559-4

Radanliev, P., Roure, D.D., Page, K., Nurse, J.R.C., Montalvo, R.M., Santos, O., Maddox, L., Burnap, P.: Cyber risk at the edge: current and future trends on cyber risk analytics and artificial intelligence in the industrial internet of things and industry 4.0 supply chains. Cybersecur. Springer Nat. 3(13), 1-21 (2020d). https://doi.org/10. 1186/s42400-020-00052-8

Rajkumar, R., Lee, I., Sha, L., Stankovic, J.: Cyber-physical systems: the next computing revolution. In: Proceedings of the 47th Design Automation Conference on-DAC'10, 731. (2010). https://doi.org/ 10.1145/1837274.1837461

Rivas, A., Martín, L., Sittón, I., Chamoso, P., Martín-Limorti, J.J., Prieto, J., González-Briones, A.: Semantic analysis system for industry 4.0. Commun. Comput. Inf. Sci. 877, 537-548 (2018). https://doi.org/10.1007/978-3-319-95204-8_45

Sangiovanni-Vincentelli, A., Damm, W., Passerone, R.: Taming Dr. Frankenstein: contract-based design for cyber-physical systems * g. Eur. J. Control. 18, 217-238 (2012). https://doi.org/10.3166/ EJC.18.217-238

Shafiq, S.I., Sanin, C., Szczerbicki, E., Toro, C.: Virtual engineering object / virtual engineering process: a specialized form of cyber physical system for Industrie 4.0. Procedia Comput. Sci. 60, 1146-1155 (2015). https://doi.org/10.1016/j.procs.2015.08.166

Shi, J., Wan, J., Yan, H., \& Suo, H.: A survey of Cyber-Physical Systems. In: 2011 International Conference on Wireless Communications and Signal Processing (WCSP), pp. 1-6 (2011). https://doi. org/10.1109/WCSP.2011.6096958

Sirris and Agoria. Made Different: Factory of the Future 4.0. (2017). http://www.madedifferent.be/en/what-factory-future-40

Sittón-Candanedo, I.: A new approach: edge computing and blockchain for industry 4.0. Adv. Intell. Syst. Comput. 1004, 201-204 (2020). https://doi.org/10.1007/978-3-030-23946-6_25

Stock, T., Seliger, G.: Opportunities of sustainable manufacturing in industry 4.0. Procedia CIRP 40, 536-541 (2016). https://doi.org/ 10.1016/j.procir.2016.01.129

Stojmenovic, I.: Machine-to-machine communications with in-network data aggregation, processing, and actuation for large-scale cyberphysical systems. IEEE Internet Things J. 1(2), 122-128 (2014). https://doi.org/10.1109/JIOT.2014.2311693

The State Council People Republic of China: Made in China 2025; The State Council People Republic of China. (2017). http://engli sh.gov.cn/2016special/madeinchina2025/

Wahlster, W., Helbig, J., Hellinger, A., Stumpf, M. A. V., Blasco, J., Galloway, H., \& Gestaltung, H: Recommendations for Implementing the Strategic Initiative INDUSTRIE 4.0. (2013). http://www. acatech.de/fileadmin/user_upload/Baumstruktur_nach_Website/ Acatech/root/de/Material_fuer_Sonderseiten/Industrie_4.0/Final_ report_Industrie_4.0_accessible.pdf

Wan, J., Cai, H., Zhou, K.: Industrie 4.0: Enabling technologies. In: Proceedings of 2015 International Conference on Intelligent Computing and Internet of Things, pp. 135-140 (2015). https://doi.org/ 10.1109/ICAIOT.2015.7111555

Zhu, Q., Rieger, C., \& Basar, T. A hierarchical security architecture for cyber-physical systems. In: 2011 4th International Symposium on Resilient Control Systems, pp. 15-20 (2011). https://doi.org/10. 1109/ISRCS.2011.6016081

Publisher's Note Springer Nature remains neutral with regard to jurisdictional claims in published maps and institutional affiliations.

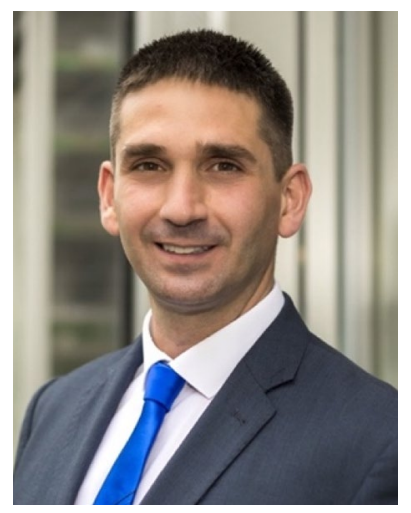

Petar Radanliev is a Post-Doctoral Research Associate at the University of Oxford. $\mathrm{He}$ obtained his Ph.D. at University of Wales in 2014 and continued with Postdoctoral research at Imperial College London, Massachusetts Institute of Technology, University of Cambridge and University of Oxford. His current research focusses on artificial intelligence, internet of things, and cyber risk analytics at the edge.

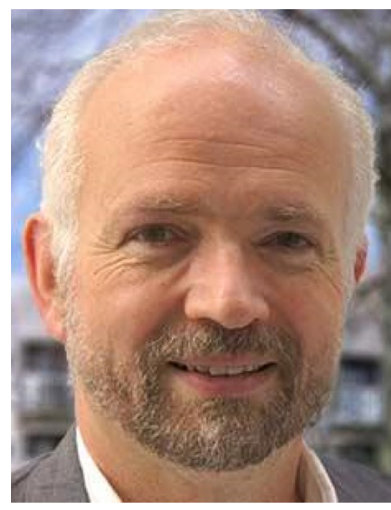

David De Roure is a Professor of e-Research at University of Oxford. He obtained his Ph.D. at University of Southampton in 1990 and went on to hold the post of Professor of Computer Science, later directing the UK Digital Social Research programme. His current research focusses on social machines, Internet of Things and cybersecurity. He is a Fellow of the British Computer Society and the Institute of Mathematics and its Applications.

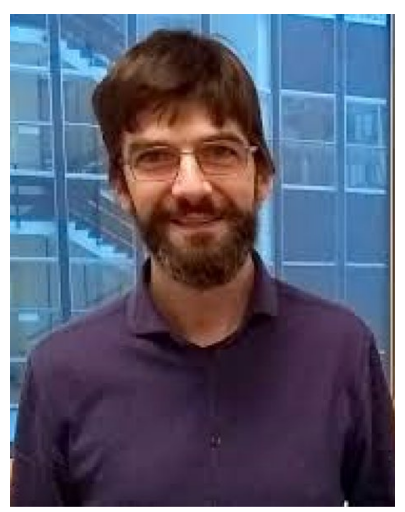

Dr Razvan Nicolescu is a digital anthropologist with an interest in understanding the social impact of new information and communication technologies. His research focuses on the relation between digital technology and political economy, ideology, governance, social change, social and economic inequality, normativity, feelings and ideals.

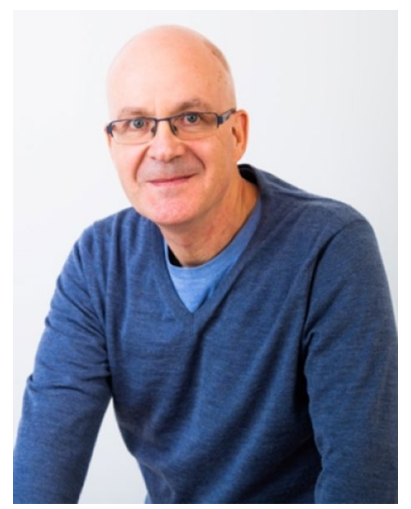

Michael Huth is a Professor of Computer Science in the Department of Computing, Imperial College London. His research focuses on Cybersecurity, Cryptography, Mathematical Modeling, and Formal Verification with applications in Machine Learning, FinTech, and Internet of Things. 


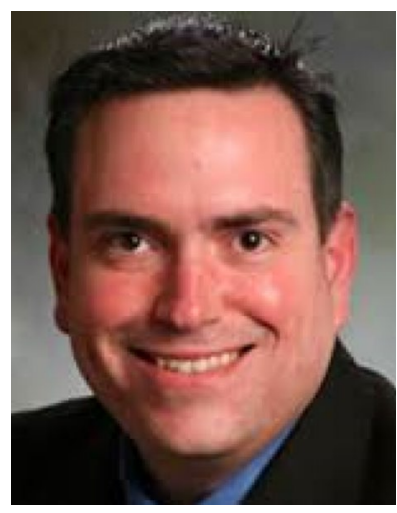

Omar Santos is a Principal Engineer at Cisco Systems and an active member of the cyber security community, where he leads several industry-wide initiatives and standards bodies. His active role helps businesses, academic institutions, state and local law enforcement agencies, and other participants dedicated to increasing the security of their critical infrastructures. 